\title{
Cultural transmission and persistence of entrepreneurship
}

\author{
G. Olcina $(\mathbb{D})$ E. M. Tur • L. Escriche
}

Accepted: 25 July 2018/Published online: 24 August 2018

(C) The Author(s) 2018

\begin{abstract}
This paper contributes to explain the persistence of differences in levels of entrepreneurship within and across countries. We provide an explanation based on the dynamic interplay between purposeful intergenerational transmission of preferences for entrepreneurship and public administration efficiency. Individuals vote on taxes, and the collected taxes fund the civil servants' wages. The performance of the administration generating an efficient normative and regulatory environment, affects the success of entrepreneurship. We show that an economy can
\end{abstract}

\section{G. Olcina}

Faculty of Economics, University of Valencia and ERICES, Avda dels Tarongers s/n, Valencia, Spain

e-mail: Gonzalo.Olcina@uv.es

E. M. Tur $(\bowtie)$

School of Innovation Sciences, Eindhoven University

of Technology, Eindhoven, Netherlands

e-mail: E.M.Mas.Tur@tue.nl

E. M. Tur

INGENIO (CSIC- UPV), Universitat Politècnica de

València, Valencia, Spain

\section{E. M. Tur}

Institute of Innovation and Entrepreneurship,

School of Business, Law and Economics,

University of Gothenburg, Gothenburg, Sweden

L. Escriche

University of Valencia and ERICES, Valencia, Spain

e-mail: Luisa.Escriche@uv.es reach two different long-run equilibria: a traditional equilibrium, with a low proportion of entrepreneurs, high taxes and an inefficient administration and, an entrepreneurial equilibrium with a high proportion of entrepreneurs and, lower taxes but enough to implement an efficient administration. The equilibrium achieved depends on the tax policy followed by the different generations. If decisions are made by majority voting in a myopic way, then the initial conditions of the society become crucial. This result explains persistence: an economy evolves around similar levels of entrepreneurship unless some reforms are implemented.

Keywords Entrepreneurship .

Cultural transmission - Entrepreneurial preferences .

Tax policy $\cdot$ Public administration efficiency

JEL Classification $\mathrm{L} 26 \cdot \mathrm{Z} 10 \cdot \mathrm{D} 01 \cdot \mathrm{H} 20$

\section{Introduction}

Entrepreneurship is a key aspect of economic dynamism as it determines productivity, innovation, and economic growth (see Schumpeter 1934; Wennekers and Thurik 1999; Minniti 1999; Audretsch and Thurik 2001, for example). ${ }^{1}$ Reynolds et al. (1999)

\footnotetext{
${ }^{1}$ See Wennekers and Thurik (1999) for a survey of how economic growth is linked to entrepreneuship.
} 
show that variations in rates of entrepreneurship may account for one third of the variation in economic growth.

The persistent difference in entrepreneurship within or across countries is a well-known stylized fact. Comparing countries, Freytag and Thurik (2007) show differences that endure for more than four decades, so the ranking between countries is quite stable (Reynolds et al. 2002). ${ }^{2}$ Concerning regions, Fritsch and Wyrwich (2014), for example, observe that the regional differences in Germany tend to be persistent as long as periods of 80 years, despite abrupt and drastic changes in the political-economic environment. This is not an isolated case since, as these authors point out, the regional start-up rates tend to be relatively persistent over periods of one or two decades in other regions as the Netherlands (van Stel and Suddle 2008), Sweden (Andersson and Koster 2011), the UK (Mueller et al. 2008), and the USA (Acs and Mueller 2008).

This paper presents a theoretical model that explains the persistence of differences in levels of entrepreneurship among economies. Our model takes into account the interaction between intergenerational transmission of entrepreneurial traits (culture) and efficiency of the administration (institutions). We obtain that an economy can converge to two different long-run equilibria. The first one is a traditional economy, with few entrepreneurs, high taxes and an inefficient administration. The second one is an entrepreneurial economy with predominantly entrepreneurial traits, lower taxes and a more efficient administration and a higher per capita income. We show that the equilibrium achieved depends completely on the tax policy followed by the different generations.

\subsection{Evidence and related literature}

Culture and institutions play a crucial role in explaining the level of entrepreneurship and especially the persistence of entrepreneurship (Wennekers and Thurik, 1999; Wennekers et al. 2005, for instance). As Freytag and Thurik put it (2007, p.121), "the persistent differences between countries point to non-economic

\footnotetext{
${ }^{2}$ Freytag and Thurik (2007) present an illustrative figure with the development of the rate of entrepreneurship for six countries of the 23 of the Compendia data set (van Stel et al. 2005) from 1973 to 2006.
}

causes, such as cultural factors, which have a tendency to remain relatively stable over time." We understand culture as the prevailing norms or values of an economy, whereas the institutions refer to the rules and laws of the environment where the businesses are conducted. $^{3}$

Entrepreneurship and culture. The values or preferences of an individual affect the decision to become an entrepreneur. These values can be risk tolerance, autonomy, striving for independence, mastery, individualism, or an aggregate trait that we will name as preferences for entrepreneurship. Many studies show that entrepreneurial preferences are transmitted among generations (Chlosta et al. 2012; Dohmen et al. 2011; Laspita et al. 2012). For example, a crucial determinant of entrepreneurship, willingness to take risk, is transmitted from parents to children (Dohmen et al. 2011 and De Paola, 2012). Wyrwich (2015) studies the relationship between entrepreneurship and mastery, in the sense of challenging existing conditions, finding evidence of an intergenerational transmission of values from parents to children. Hundley (2006) provides support for the effects of skills and values that are specifically acquired from exposure to a self-employed parent on the self-employment choice. Lindquist et al. (2015) show that parental entrepreneurship increases the probability of children's entrepreneurship by about $60 \%$ and present suggestive evidence in favor of role modeling. Hoffmann et al. (2015) also found evidence about the parental role models in entrepreneurship. Economic theory also provides an extended literature on the intergenerational transmission of values since the pioneering paper by Bisin and Verdier (2001). ${ }^{4}$ Recently, Chakraborty et al. 2016 have also considered this framework to connect culture to entrepreneurship and economic growth.

Entrepreneurship and institutions.Besides culture, another determinant of entrepreneurship is the quality of the institutions (Acs and Amorós 2008). Institutions are crucial because of their role in ensuring the protection of property rights, the objective resolution

\footnotetext{
3"'Relevant institutions include fiscal legislation (tax rates and tax breaks), the social security system influencing the rewards and the risks of entrepreneurship, and the administrative requirements for starting a new business." (Wennekers et al. 2005, p. 300)

${ }^{4}$ See Bisin and Verdier (2011b) for a survey of this literature.
} 
of contracts and other legal disputes, and the government's transparency (van Stel et al. 2005). The OECDEurostat Entrepreneurship Indicator Programme (EIP, 2009) indicates that entrepreneurship requires a good, clear, and enforceable regulatory framework. Afonso et al. (2005) elaborate an Administration Opportunity Indicator that takes into account corruption, red tape (concerning regulatory environment), quality of the judiciary (concerning the confidence in the Administration of justice), and the size of the shadow economy. The correlation between the entrepreneurship rate and this Administration Opportunity Indicator offers a positive and significant value of $0.42 .^{5}$ Klapper et al. (2010) also find a positive and significant relationship between both the "ease of doing business index" and the entry and new firm density rates per country. ${ }^{6}$ They estimate that for every 10 percentage point decrease in entry costs, density and entry rate increase by about $1 \%$.

\subsection{Key features of the model}

Our model explicitly analyzes the interaction among preferences and institutions when preferences are heterogeneous in the population and evolve over time. In this Section, we describe its key features.

Concerning the first element, preferences, we consider that each adult chooses between becoming an entrepreneur or not, in which case, he will work as a civil servant or as a routine producer. The choice depends on his preferences. Preferences are transmitted among generations during the socialization process. As in Bisin and Verdier (2011b), the model considers that the values or attitudes may be transmit-

\footnotetext{
${ }^{5}$ Correlation between Total Entrepreneurial Activity Rate (TEA) and Administration Opportunity Indicator for those countries that appear in both sources of data in 2000. Source: own elaboration based on data from Afonso et al. (2005) and Global Entrepreneurship Monitor, GEM (Autio, 2005). TEA: proportion of adults involved in creation of nascent firms (3 months) and proportion involved in surviving firms (42 months).

${ }^{6}$ The Doing Business Report includes a ranking of this "ease of doing business index". A high position in the ease of doing business ranking means that the regulatory environment is more conducive to the starting and operation of a local firm. The index is constructed as the simple average of the countries' percentile rankings on 10 topics: Starting a business, Dealing with licenses, Employing workers, Registering property, Getting credit, Protecting investors, Paying taxes, Trading across borders, Enforcing contracts, and Closing a business.
}

ted (at a cost) from parents to children or by society at large, in other words, there exists direct transmission and oblique transmission. Parents try to shape the preferences of their children taking into account the potential gains of the children's occupational choice when they become adults. If parents do not succeed in transmitting their chosen preferences, then children acquire preferences from the social environment where they grow up.

Concerning the second element, the quality of institutions, we consider that the efficiency of the administration determines the expected profits from entrepreneurial activity. Specifically, if an individual decides to become an entrepreneur and start a risky project, the probability of success will crucially depend on the level of efficiency and the size of the administration. By efficiency of the administration, we mean the effort made to generate a friendly normative and regulatory framework for business, although it can have other alternative interpretations, such as the absence of corruption in the public sector. ${ }^{7}$ Bureaucracy (and civil servants) will make its decision on efficiency pursuing its own interests depending on the total payoff they obtain. Wages of civil servants are paid with collected taxes; it is assumed that there is a balanced public budget. Specifically, the model assumes that only entrepreneurs are net contributors. Therefore, entrepreneurs face a trade off: high taxes mean that they appropriate a low proportion of their income, but it also means that the efficiency of the administration is high. Consequently, the expected gross profits can be high. The level of taxation is decided by some political process. In this paper, it will be chosen by majority voting, but obviously, we can also make clear predictions to political situations where the decisive political agent is not necessarily the median voter.

\footnotetext{
${ }^{7}$ To interpret the efficiency of the Administration as absence of corruption, the distribution of ethics among the officials should be considered. This can be implemented by considering that civil servants could be either honest or dishonest as in Hauk and Saez-Marti (2002) or that they may exhibit public service motivation or not as in Delfgaauw and Dur (2008). A more general model will analyze the coevolution of these traits and the preferences for entrepreneurship. In this paper we focus on the efficiency of the Administration as observable and valuable items which can be measured by indicators such as for instance, the "easy doing business".
} 


\subsection{Main findings}

The main result of the paper is that the persistent differences in entrepreneurship across economies can be explained by two factors: the initial conditions of the economy and the taxation level on entrepreneurial earnings. We first show that an economy can reach two different long-run equilibria where the socialization efforts of entrepreneurs and non-entrepreneurs parents to transmit their preferences are balanced. The first equilibrium is a traditional economy, with a low proportion of entrepreneurs, high confiscatory taxes, and an inefficient administration. The second possible equilibrium is an economy with predominantly entrepreneurial traits, lower taxes (but high enough to implement an efficient administration), and a higher per capita income. Taxes will be higher and the public sector will be less efficient in a traditional equilibrium, corroborating that high levels of taxation, corruption, and bureaucratic obstacles to start a business can discourage entrepreneurship (Lee and Gordon, 2005; Klapper et al. 2006, 2010; Ciccone and Papaioannou, 2007; Cullen and Gordon, 2007; Djankov et al. 2010).

Our model shows that the tax rate on entrepreneurial profits implemented by the previous generations completely determines whether an economy achieves a traditional equilibrium or an entrepreneurial equilibrium. If tax decisions are made by majority voting in a myopic way, then the initial conditions of the economy become crucial. That is, for an economy with an initial majority of non-entrepreneur individuals, the dynamics will move the economy towards the non-entrepreneurial steady state, as they will vote for the highest taxes. These confiscatory tax policy reinforces the superior incentives of non-entrepreneurs to transmit their preferences consolidating their majority. Conversely, an economy with a majority of entrepreneurs will set up a moderate tax on entrepreneurial profits just high enough to afford an efficient administration, and the dynamics will move the economy towards the entrepreneurial steady state. This efficient tax policy guarantees that entrepreneurs have enough incentives to transmit their preferences.

In the end, if individuals vote myopically, the ultimate determinant of where the economy establishes in the long run is the initial proportion of entrepreneurs and productivity. This fact explains persistence: an economy evolves around similar levels of entrepreneurship as in the initial situation unless some structural changes are implemented.

However, if individuals are forward-looking and they are concerned about the welfare of future generations, they might try to implement some tax reform in order to drive the economy towards an entrepreneurial society. In the entrepreneurial equilibrium, both entrepreneurs and non-entrepreneurs obtain a higher payoff than in the traditional one. We discuss different alternatives in order to establish a credible intergenerational commitment to never set confiscatory taxes in the future and to compensate the short-run losses for non-entrepreneurs with a subsidy.

The paper is organized as follows. Section 2 introduces the static model, describing the game played by each generation. Section 3 characterizes the different equilibria of the game played within a generation between administration and voters. Section 4 describes the cultural transmission of preferences and the evolution of the proportion of entrepreneurs in the population. Section 5 characterizes the long-run equilibria of the society. Section 6 compares the levels of income and social welfare obtained in the different steady-state equilibria. Finally, Section 7 concludes and discusses some policy proposals.

\section{The model}

We consider overlapping generations of individuals that live two periods. During the first period, each individual is socialized in some cultural traits and, at the beginning of the second period, as an adult, he becomes active and enters the labor market.

A proportion $q \in[0,1]$ of the individuals are of entrepreneurial type $(E)$, and the rest, $(1-q) \in$ $[0,1]$, are of non-entrepreneurial type $(N)$. The nonentrepreneurs work as civil servants or in a traditional sector with a fixed payoff. The civil servants are a proportion $\alpha$ of the population and, therefore, $\alpha \in(0,1)$ denotes the size of the administration.

\subsection{Payoffs}

The workers that join the traditional sector will receive a fixed monetary payoff denoted by $R>$ 0 . However, entrepreneurship is a risky activity. The income is $H>R$ in case of success and zero in case 
of failure. If the entrepreneur fails, his payoff is lower that the wage in a routine production activity $R$.

The success of the entrepreneurial activity depends on the legal and normative framework where this activity is conducted, and the institutional environment depends on the efficiency of the administration, denoted by $e .{ }^{o}$ We consider that the administration efficiency $e$ crucially affects the probability of success denoted by $p$ and for the activity to be risky indeed; this probability of success $p$ has to be lower than 1 . Additionally, there is some interaction between the level of efficiency and the size of the administration. We assume that the success of the entrepreneurial activity depends both on the efficiency and the size of the administration, with an inverted- $U$ relationship. Thus, very small or very big administrations will lead to lower probabilities of success. ${ }^{8}$ Summarizing, we assume that the probability of success of the entrepreneurial activity is given by the following:

$p=e \alpha(1-\alpha)$.

Therefore, the expected income $\pi$ of the risky activity is $\pi=p H$, where $H$ can be interpreted as the productivity of the entrepreneurial sector. Moreover, entrepreneurs pay taxes, $\tau$, so that the net monetary income of an entrepreneur is as follows:

$y_{E}=(1-\tau) H p$.

Collected taxes fund the public administration. We consider that only entrepreneurs pay taxes. It could be considered that all workers pay taxes and receive services in return but, in any case, there would be net contributors and net beneficiaries. Under our assumption, the entrepreneurs are net contributors. Moreover, the tax rate is decided by majority, through a voting process.

We consider that the public administration is run by a single entity, and we assume that its managers decide on the level of efficiency and size of the administration $(e, \alpha)$ with the objective of maximizing the income of civil servants or bureaucrats. There is no agency problem within the administration, whoever holds power on behalf of the bureaucracy cares about the average welfare of the group as a whole. The level of efficiency

\footnotetext{
${ }^{8}$ Even if the administration is efficient, if civil servants are very few the support given to the entrepreneurs activity is likely to remain limited. Similarly, an oversized public sector would not contribute to the success of entrepreneurial activity.
}

can be achieved at a cost which increases in the size of the administration, that is, the number of civil servants $\alpha$. In particular, it has a cost given by $c(e)=\alpha \frac{\beta e^{2}}{2}$, $\forall e \in[0,1)$. Therefore, the managers of the administration choose the level of efficiency $e$ and the size of the administration $\alpha$ that maximize the following:

$\tau \operatorname{Hqe} \alpha(1-\alpha)-\alpha \frac{\beta e^{2}}{2}$

which is the difference between public income and the cost to implement the regulatory framework. For simplicity, we assume that the collected taxes minus the cost of efficiency is divided equally among the civil servants. Therefore, officials' wage is given by the following:

$y_{C}=\tau H q e(1-\alpha)-\frac{\beta e^{2}}{2}$.

Civil servants' wages increase with three factors: (i) the level of taxes, $\tau$, (ii) the level of expected profits which, in turn, depends on the administration efficiency $e$, and (iii) the proportion of entrepreneurs $q$ . If there is a high proportion $q$ of entrepreneurs, the proportion of taxpayers will increase. However, if the size of the administration $\alpha$ increases, the number of recipients also increases: each civil servant receives a smaller fraction of the collected taxes.

We abstract from the free-riding problem of civil servants effort and consider that there is a minimum observable effort that is enforceable and that if it is not met by the civil servant, he will be fired. Then, the public agency offers an enforceable contract in which a wage level $y_{C}$ is specified, along with a minimum effort level. (See Delfgaauw and Dur, 2008, or Forquesato, 2016, for an analysis on the incentives and workers' motivation in the public sector or organizations).

Finally, the monetary payoff of an onentreprepreneurial individual is given by the following:

$y_{N}=\frac{\alpha}{1-q} y_{C}+\left(1-\frac{\alpha}{1-q}\right) R$

where $y_{C}$ and $R$ are the payoffs as civil servants and routine producers, respectively; and the fractions $\frac{\alpha}{1-q}$ and $1-\frac{\alpha}{1-q}$ are the probabilities of a nonentrepreneurial individual to work as civil servant or routine producer, respectively, when $(1-q)>\alpha$. If $(1-q) \leq \alpha$, the probability of a non-entrepreneurial 
individual to work as civil servant will be one and, therefore $y_{N}=y_{C}$.

\subsection{Preferences}

Entrepreneurs positively value the participation in a risky activity and obtain a psychological payoff denoted by $\gamma>0$. This non-pecuniary benefit may correspond to social status, the satisfaction of starting your own business, the flexibility and autonomy of self-employment, etc. Moskovitz and Vissing-Jorgensen (2002) estimate that entrepreneurs non-pecuniary benefits amount on average to some $150 \%$ of the entrepreneur's annual income. The nonentrepreneurial individuals, in contrast, obtain a psychological disutility $\gamma>0$ from undertaking a risky activity. This type of individuals has a negative view of things, such as taking risks, not having a permanent job, etc. ${ }^{9}$

We use a simple kind of preferences to characterize the types $E$ and $N$. In particular, we consider that the individuals have a linear utility function that depends on both the expected monetary payoff and on the nonpecuniary benefit they obtain for their activity:

$$
\begin{aligned}
& U_{E}=y_{E}+\gamma 1_{E}, \\
& U_{N}=y_{N}-\gamma 1_{E}
\end{aligned}
$$

where $y_{i}, i \in\{E, N\}$, denotes the expected monetary payoff and $1_{E}$ is the indicator function of entrepreneurial activity $\left(1_{E}=0\right.$ if the individual is type $N$ and $1_{E}=1$ if he is type $E$ ).

A priori, both types could choose to carry out either the risky or the non-risky activity. However, taking into account the evidence about the intergenerational transmission of entrepreneurship, we consider that the individual's type determines the activity he chooses.

We make an assumption on the relationship between the wage in the traditional sector $R$ and the psychological payoff $\gamma$ of entrepreneurship. In particular, we establish a lower bound on this psychological payoff:

$$
(1-\alpha) R<\gamma \quad \text { Assumption } 1
$$

\footnotetext{
${ }^{9} \mathrm{We}$ assume that the two psychological payoffs are the same. That is, the utility of engaging in the risky activity for the entrepreneurs is the same as the disutility of this activity for the non-entrepreneurs. Although this assumption is not strictly necessary, it simplifies the process of obtaining and interpreting the results.
}

Assumption 1 implies that we will not consider in our analysis the less interesting case where the psychological payoff from entrepreneurship is so low compared with the payoff in the traditional sector that parents will always prefer that their offspring become non-entrepreneurs under any circumstance.

\subsection{The game between administration and voters}

The timing of each generation's game is as follows. First, taxes are decided by majority voting, that is, individuals vote for the level of taxes $\tau \in[0,1]$ that will fund the administration. After voting, the administration decides about efficiency and size of the administration. Then, the entrepreneurial individuals start their business and the non-entrepreneurial individuals find a job in either the public or the traditional sector. Finally, all agents receive the payoffs.

There is a strategic interaction between the administration and entrepreneurs. The administration needs the success of the entrepreneurs to guarantee the public income and, obviously, the salary of the officials. And in turn, entrepreneurs need the efficiency of the administration to be successful in their activity.

\section{Equilibria in each generation}

In this section, we analyze the equilibrium of the game played in each generation between administration and voters. Firstly, we obtain both the level of efficiency and size of the administration given any tax rate decided by the voters and, secondly, we analyze the tax rate that each type will vote anticipating these administration decisions.

The administration chooses the level of efficiency and size of the public sector $(e, \alpha)$ that ensures the maximum total payoff of the bureaucracy. Maximizing (2) with respect to $e$ and $\alpha$, subject to $(1-q) \geq \alpha$, it follows that the interior solution of each variable as a function of the other variable, is given by the following:

$$
\begin{aligned}
& e(\alpha)=\frac{\tau q H(1-\alpha)}{\beta}, \\
& \alpha(e)=\frac{\tau 2 q H-\beta e}{4 \tau H \beta} .
\end{aligned}
$$

Notice that the smaller the size of administration, the higher is the level of efficiency chosen by its manager and vice versa. 
Solving for the optimal levels $\left(e^{*}, \alpha^{*}\right)$, we obtain that for $1-q \geq 1 / 3$,

$e^{*}=\tau \frac{2 q H}{3 \beta}$,

$\alpha^{*}=\frac{1}{3}$.

In the case that $1-q<1 / 3$, then all non-entrepreneurs work as civil servants: $\alpha^{*}=1-q$ and $e^{*}=\tau \frac{q^{2} H}{\beta}$.

Therefore, there exists an optimal size of the administration, while its efficiency increases (i) with the tax rate $\tau$, since bureaucrats acquire a higher proportion of the entrepreneurs' profits, (ii) with the proportion entrepreneurs $q$ (because they are tax payers) and, finally (iii) with the productivity $H$.

Second, we analyze the results of the voting process on taxes. Entrepreneurs face a trade off: high taxes mean that they appropriate a low proportion of their income but high taxes also improve the efficiency of the administration, and then increase the probability of success of the entrepreneurial activity. Consequently, even if they do not appropriate all the benefits of the risky activity, they vote for an intermediate tax rate. Nonetheless, the earnings of non-entrepreneurs depend positively on taxes, since a share of those non-entrepreneurs are civil servants. Consequently, non-entrepreneurs prefer a higher tax compared to entrepreneurs.

Formally, each type votes the tax rate that maximizes his payoff, anticipating the efficiency chosen by the bureaucracy. Entrepreneurs choose the tax rate that maximizes

$y_{E}=(1-\tau) \pi= \begin{cases}\tau(1-\tau) \frac{4 q H^{2}}{27 \beta} & \text { if } q \leq 2 / 3, \\ \tau(1-\tau) \frac{H^{2} q^{3}(1-q)}{\beta} & \text { if } q>2 / 3 .\end{cases}$

These payoff functions have a maximum in $\tau=1 / 2$. On the other hand, the non-entrepreneurs vote for the tax rate $\tau \in[0,1]$, which maximizes their expected payoff

$y_{N}= \begin{cases}\frac{\alpha^{*}}{(1-q)} y_{C}+\left(1-\frac{\alpha^{*}}{(1-q)}\right) R=\frac{2 \tau^{2} H^{2} q^{2}}{9 \beta}+\frac{2-3 q}{3(1-q)} R & \text { if } q \leq 2 / 3, \\ y_{C}=\frac{\tau^{2} q^{4} H^{2}}{2 \beta} & \text { if } q>2 / 3 .\end{cases}$

These payoffs are increasing with $\tau$ and, consequently, the non-entrepreneurs vote for $\tau=1$. As it can be expected, the non-entrepreneur individuals vote for the maximum level of taxes, that is, confiscatory taxes.
The main result of this section is stated below and described formally in the Appendix.

Proposition 1 There are two possible equilibria in each generation depending on which of the two types is prevalent in the population, (i) an entrepreneurial equilibrium if entrepreneurs are majority $(q \geq 1 / 2)$ with a low tax rate $\tau=1 / 2$ and (ii) a traditional equilibrium if non-entrepreneurs are majority $(q<1 / 2)$ with a high tax rate $\tau=1$.

Proof See Appendix.

If non-entrepreneurs are the majority of the population, they win the voting process and taxes will be confiscatory. In this case, bureaucracy appropriates the whole entrepreneurs' earnings and entrepreneurs obtain only their psychological payoff. Conversely, if entrepreneurs are the majority of the population, they will vote for an intermediate tax rate and the monetary profits from entrepreneurship will be shared between entrepreneurs and the bureaucracy.

\section{Cultural transmission process}

As obtained in the previous section the equilibrium played by each generation is fully determined by the existing distribution of preferences in the population. But this distribution might change over time because of a process of intergenerational cultural transmission of preferences. Having established the payoff of individuals with different preferences in the equilibria, parents face the problem of choosing to transmit his cultural trait (preferences for entrepreneurship or not) to his offspring.

\subsection{The socialization process and the dynamics of preferences for entrepreneurship}

We draw from the model of cultural transmission by Bisin and Verdier (2001), which is the economic version of the anthropological model by Cavalli-Sforza and Feldman (1981). The type of an individual (i.e., entrepreneur or not) will be an acquired trait derived from the socialization process. Individuals will live through two periods: as children and as adults. During their childhood, each individual's preference is shaped by both his parents and society at large. As an adult, 
he enters the labor market and becomes part of the productive economy in his generation's game.

Each adult has one child in the second period of his life and tries to transmit the values or preferences that he believes are the most valuable. Therefore, each adult makes a decision on a costly socialization effort to influence his child's preferences.

Let $d_{t}^{i} \in[0,1)$ be the socialization effort made by a parent of type $i$ at generation $t, i \in\{E, N\}$. Socialization occurs in two steps. A child is first directly exposed to the parent's preferences and is socialized to these preferences with probability $d_{t}^{i}$ (vertical transmission). If this direct socialization is not successful, with probability $1-d_{t}^{i}$, she is socialized to the preferences of a role model picked at random in the population (oblique transmission). The transition probabilities $P_{t}^{\mathrm{ij}}$ that a parent of type $i$ will have a child of type $j$, if the proportion of entrepreneurs is $q_{t}$, are given by the set of equations:

$$
\begin{aligned}
& P_{t}^{\mathrm{EE}}=d_{t}^{E}+\left(1-d_{t}^{E}\right) q_{t} \\
& P_{t}^{\mathrm{EN}}=\left(1-d_{t}^{E}\right)\left(1-q_{t}\right) \\
& P_{t}^{\mathrm{NN}}=d_{t}^{N}+\left(1-d_{t}^{N}\right)\left(1-q_{t}\right) \\
& P_{t}^{\mathrm{NE}}=\left(1-d_{t}^{N}\right) q_{t} .
\end{aligned}
$$

For instance, $P_{t}^{\mathrm{EE}}$ is the probability that a child of an entrepreneur parent is socialized to entrepreneurial preferences. Namely, with probability $d_{t}^{E}$, he adopts his parent preferences and with probability $\left(1-d_{t}^{E}\right)$ he adopts these preferences of other entrepreneurial individual with whom he is randomly matched.

Given the transition probabilities $P_{t}^{\mathrm{ij}}$, the proportion $q_{t+1}$ of entrepreneurs in period $t+1$ is described in equation (9) and the dynamic evolution of the distribution of preferences is given by (10):

$q_{t+1}=q_{t}+q_{t}\left(1-q_{t}\right)\left(d_{t}^{E}-d_{t}^{N}\right)$,

$\Delta q_{t}=q_{t}\left(1-q_{t}\right)\left(d_{t}^{E}-d_{t}^{N}\right)$.

Notice that the proportion of entrepreneurs will increase from one generation to another if, and only if, the socializing effort of the entrepreneur parents is greater than that of the non-entrepreneur parents (equation 11). Likewise, the proportion of entrepreneurs will fall if, and only if, the socializing effort of the entrepreneur parents is lower than that of the non-entrepreneur parents (equation 12).

$$
\begin{aligned}
& \Delta q_{t}>0 \Longleftrightarrow d_{t}^{E}-d_{t}^{N}>0 \\
& \Delta q_{t}<0 \Longleftrightarrow d_{t}^{E}-d_{t}^{N}<0
\end{aligned}
$$

\subsection{The socialization effort choice of parents}

Parents are imperfect altruists towards their children, according to the notion of "imperfect empathy" described by Bisin and Verdier (2001). That is, they are concerned about their children's welfare, but they evaluate the utility that their children will receive through the lens of their own preferences. We denote $V^{\mathrm{ij}}$ the utility a type $i$ parent assigns to a child of type $j$. This utility will depend on the expectation about the distribution of preferences in the next generation. We will assume that parents have adaptive or backwardlooking expectations, believing that the proportion of entrepreneurs will be the same in the next generation as in the current generation.

The socialization effort has a cost: parents have to invest in their children's education, spend time with them, choose the appropriate neighborhood, or school, etc. For simplicity, we consider that the cost is quadratic $c\left(d_{t}^{i}\right)=\frac{k\left(d_{t}^{i}\right)^{2}}{2}$, with $k>0$, even though the results are qualitatively identical with any increasing convex function. Parents of type $i$ choose the socialization effort $d_{t}^{i}$ at generation $t$ that maximizes the following:

$\max _{d_{t}^{i}}\left\{P_{t}^{\mathrm{ii}} V^{\mathrm{ii}}+P_{t}^{\mathrm{ij}} V^{\mathrm{ij}}-c\left(d_{t}^{i}\right)\right\}$.

The optimal parents' socialization efforts are as follows: ${ }^{10}$

$$
\begin{aligned}
d_{t}^{* E} & =\frac{1}{k} \Delta V^{E}\left(1-q_{t}\right) \\
d_{t}^{* N} & =\frac{1}{k} \Delta V^{N} q_{t} .
\end{aligned}
$$

As in the literature, we call $\Delta V^{i}=V^{\mathrm{ii}}-V^{\mathrm{ij}}$ the value of cultural assimilation. This value of cultural assimilation is the net gain from socializing your child to your own preferences. Hence, the parents' socialization effort depends on two factors: (i) the probability of oblique transmission and (ii) the value that parents

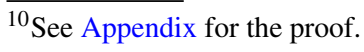


confer to have a child of their own type instead of the other type. Concerning the first one, optimal socialization efforts vary according to the probability of oblique transmission. That is, the more individuals of a type there are in the society, the lower the effort these parents invest in vertical socialization. Since oblique socialization is not costly, the parents of the predominant type can trust that their children will be socialized toward their own type by other individuals in the society. This is a standard property of the Bisin and Verdier (2001) model of transmission of preferences.

With respect to the second factor, expressions (14 and 15) show that the value of cultural assimilation influences the socializations efforts of parents. The level of cultural assimilation for the different types depends on the fiscal regime, which is decided by the majority type in the population. These values of cultural assimilation are computed in the Appendix and are presented here to facilitate the explanation. In a non-entrepreneurial economy $\left(q_{t}<1 / 2\right)$, where the majority of non-entrepreneurs vote for confiscatory taxes $\tau=1$, the values are as follows:

$\Delta V^{E}=\gamma-y^{N}$ and $\Delta V^{N}=\gamma+y^{N}$.

For instance, the value of cultural assimilation of an entrepreneur $\Delta V^{E}$ in an economy with a majority of non-entrepreneurs will be the difference between the value of having a child with his own preferences, $\gamma$ and the value of having a child with nonentrepreneurial preferences, $y^{N}$.

In an entrepreneurial economy $\left(q_{t} \geq 1 / 2\right)$, where the majority of entrepreneurs vote for nonconfiscastory taxes $\tau=1 / 2$, the values of cultural assimilation are now given by the following:

$\Delta V^{E}=\gamma+\left[y^{E}-y^{N}\right]$ and $\Delta V^{N}=\gamma-\left[y^{E}-y^{N}\right]$.

In these expressions, we can see that the value for a parent to transmit their own preferences depends crucially on the expected payoff for their children. In the next section, we explain in greater detail how the values of cultural assimilation favors the spread of a particular trait.

In short, preferences for entrepreneurship evolve over time depending on the relative optimal effort of both types of parents. Likewise, these optimal efforts are determined by the expected payoffs as entrepreneurs or not entrepreneurs which, in turn, are

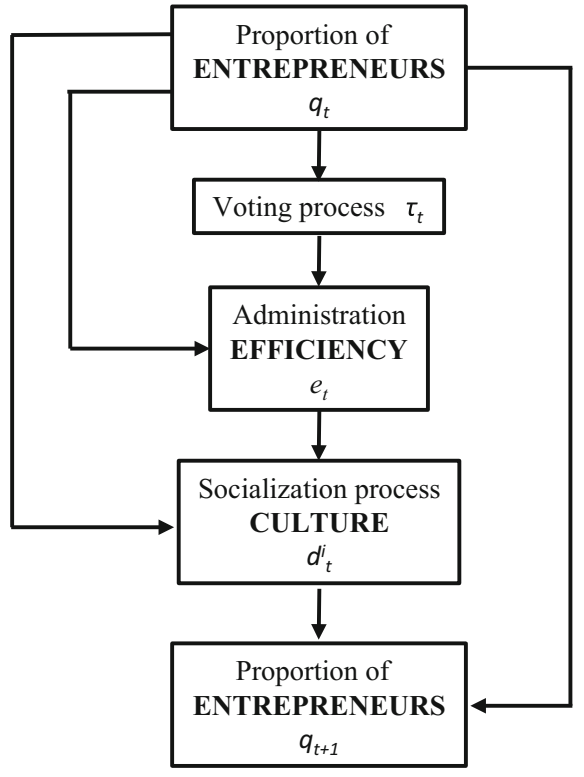

Fig. 1 The dynamical links between the Proportion of entrepreneurs, administration efficiency and Socialization process

determined by taxes and administration efficiency. A schematic illustration of the whole dynamic setting is presented in Fig. 1.

The state variable of the dynamics is the proportion of entrepreneurs in the population, $q_{t}$ in period $t$. This proportion determines the tax rate decided through the voting process, which in turn, determines the collected taxes and the level of efficiency and size of the administration. Efficiency and size of the administration determine the probability of success of the risky entrepreneurial activity. This probability of success together with the proportion of entrepreneurs $q_{t}$ and the entrepreneurial productivity $H$, jointly determine the monetary income obtained by both types in the population: entrepreneurs and non-entrepreneurs. The different types' revenues, together with the psychological payoff, determine the adults' direct socialization incentives, since they affect the net gains for transmitting your own preferences. Finally, the effect of both direct transmission incentives and oblique transmission of preferences, captured by the current distribution of preferences $q_{t}$, leads to the next generation's proportion of entrepreneurs $q_{t+1}$. In the next Section, the pattern of the distribution of preferences in the long run is analyzed. 


\section{Preferences for entrepreneurship in the long run}

The force that drives the change of the distribution of preferences is the socialization effort of both types of parents. Formally, the dynamics of the distribution of preferences is derived by substitution of the optimal education effort $d_{t}^{* E}$ and $d_{t}^{* N}$, from (14) and (15), into expression (10):

$\Delta q_{t}=q_{t}\left(1-q_{t}\right)\left(d_{t}^{* E}-d_{t}^{* N}\right)$.

A long-run equilibrium (steady state of the dynamics) is a situation in which the proportion of entrepreneurs remains constant over time, $\Delta q_{t}=0$. This can occur for two reasons. First, in a trivial way, because the society is made of a single type $\left(q_{t}=0\right.$ or $q_{t}=1$ ), although these solutions lack interest because they are not stable. ${ }^{11}$ Second, because the socializing efforts of the two types are balanced, $d_{t}^{* E}-d_{t}^{* N}=0$. As explained in the previous section, if the socialization effort of entrepreneurial parents is greater (smaller) than the effort of non-entrepreneurial, the proportion of entrepreneurial individuals will increase (decrease) from one generation to another. However, if socialization efforts equals, i.e., $d_{t}^{* E}-d_{t}^{* N}=0$, the distribution of preferences among the population remains stable.

Next, we characterize the long-run equilibria of the dynamics starting from a society with a majority of non-entrepreneurs or from a society with a majority of entrepreneurs.

\subsection{The long-run equilibrium of a non-entrepreneurial society}

In a society with a majority of non-entrepreneurs, where this majority holds up all the profits from entrepreneurship through confiscatory taxes and receive them as civil servants' income, the dynamics converges to a steady state equilibrium with a low proportion of entrepreneurs, which we call as a traditional equilibrium. The superscript $c$ is used for traditional equilibrium.

Proposition 2 For all $q_{0}<1 / 2$ the dynamics converges to a traditional equilibrium $\left(q^{c}<1 / 2\right)$, with a majority of non-entrepreneurs and a tax rate $\tau=1$.

\footnotetext{
${ }^{11}$ This a property of this kind of dynamics, see Bisin and Verdier (2011b).
}

Proof See Appendix.

In a society with a majority of non-entrepreneurs, the value of cultural assimilation and therefore the incentives for direct socialization are always higher for non-entrepreneurs than for entrepreneurs. The intuition behind this result is quite obvious: non-entrepreneurs hold up all the profits from entrepreneurship through confiscatory taxes and receive them as civil servants' income.

Nevertheless, given assumption $1((1-\alpha) R<\gamma)$, for low values of the level of entrepreneurship $q_{t}$, the income of civil servants will also be very low and so will be the difference between the values of cultural assimilation of both types. On the other hand, non-entrepreneurs trust on oblique transmission and will exert a low socialization effort, while the minority of entrepreneurs will try to compensate the effects of oblique transmission with an increased socialization effort. As a result, for low values of $q_{t}$, the optimal socialization effort of the entrepreneurs $d_{t}^{E}$ will be higher than the one of non-entrepreneurs $d_{t}^{N}$, and the share of entrepreneurship preferences will increase in the next generation. For the rest of the non-entrepreneurial region, oblique transmission is not strong enough to compensate for the increasing difference on the values of cultural assimilation $\Delta V^{N}-\Delta V^{E}$. All the previous discussion explains the directional arrows on Fig 2 for $q_{t}<1 / 2$. In Fig. 2, we can see the direction of changes in the proportion of entrepreneurs for different values of $q_{t}$. The arrows show the direction of intergenerational change.

5.2 The long-run equilibrium of an entrepreneurial society

In a society with a majority of entrepreneurs where they vote for intermediate taxes and thus share the profits from entrepreneurship with civil servants, the dynamics converges either to (i) the entrepreneurial equilibrium, denoted by $q^{e}$, with a relatively high proportion of entrepreneurs and a high administration efficiency, if entrepreneurial productivity is high enough, or to (ii) the traditional equilibrium, $q^{c}$, if entrepreneurial productivity is low. Formally,

Proposition 3 1. For all $q_{0} \geq 1 / 2$ and productivity $H<H^{\prime}$ the dynamics converges to a traditional 
Fig. 2 The dynamics of the proportion of entrepreneurs

\section{$\boldsymbol{H} \geq \boldsymbol{H}^{\prime}$}

$$
\boldsymbol{H}<\boldsymbol{H}^{\prime}
$$

equilibrium $\left(q^{c}<1 / 2\right)$, with a majority of nonentrepreneurs and a tax rate $\tau=1$.

2. For all $q_{0} \geq 1 / 2$ and productivity $H \geq H^{\prime}$ the dynamics converges to an entrepreneurial equilibrium $\left(q^{e}>1 / 2\right)$, with a majority of entrepreneurs and a tax rate $\tau=1 / 2$.

The critical value is $H^{\prime}=6 \sqrt{\beta R}$.

Proof See Appendix.

In a society with a majority of entrepreneurs voting for nonconfiscastory taxes $\tau=1 / 2$, the relationship between the values of cultural assimilation depend now on the difference in monetary payoffs obtained between entrepreneurs and nonentrepreneurs. Namely, notice that $\Delta V^{E}>\Delta V^{N}$ if and only if $y^{E}>y^{N}$.

For low values of the proportion of entrepreneurs $q_{t}$, but higher than $1 / 2$, the relation between $y^{E}$ and $y^{N}$ and the relative incentives for socialization depend on the level of entrepreneurial productivity $H$. Let us denote as $H^{\prime}$ the value of $H$ that equalizes $y^{E}$ and $y^{N}$ when $q=1 / 2$. Straightforward calculation yields that $H^{\prime}=6 \sqrt{\beta R}$.

Therefore, when the productivity from entrepreneurship is very low, $H<H^{\prime}$, the socialization effort of non-entrepreneurs parents is higher than that of entrepreneur parents even when taxes are nonconfiscatory. Preferences for non-entrepreneurship spread in the population until eventually $q_{t}$ will fall below $1 / 2$ and non-entrepreneurs will become the new majority. In this case, there will be no steady-state equilibrium where entrepreneurial preferences are majority.
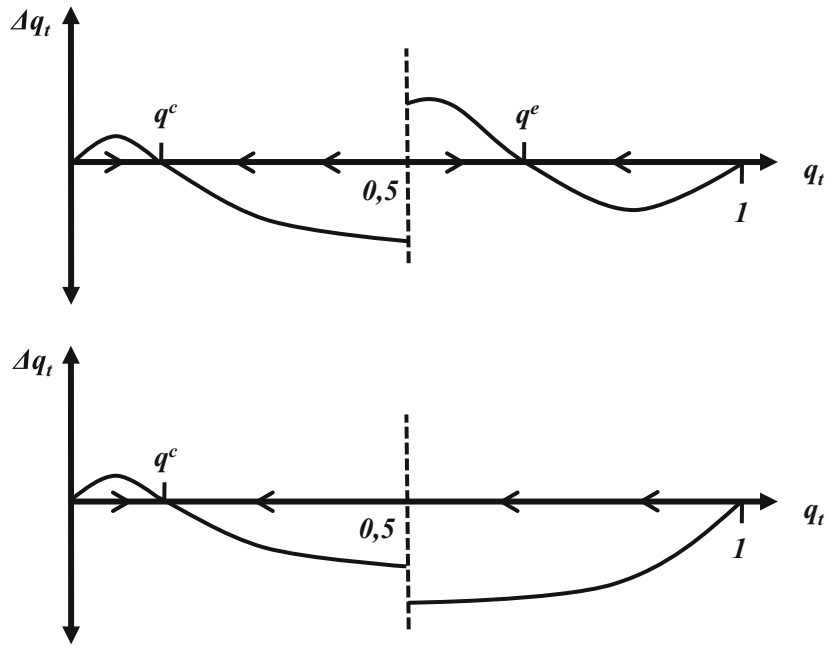

But for high enough levels of productivity, $H$ $\geq H^{\prime}$, and $q_{t}$ higher and close to $1 / 2$, the income obtained by entrepreneurs will be higher than the income obtained by individuals of the nonentrepreneur type. Consequently, the socialization effort of entrepreneurs will be higher than that of non-entrepreneurs, resulting in an increase in the next generation's proportion of entrepreneurs. Intuitively, only if the productivity of entrepreneurship $H$ is sufficiently high, entrepreneur parents will have stronger incentives to socialize their children than the incentives non-entrepreneurial parents have.

However, once high values of $q_{t}$ are reached, the monetary payoff for a non-entrepreneur becomes greater than the one obtained by an entrepreneur. The reason is that in an economy with high levels of entrepreneurship, the few existing civil servants share half of the aggregate profits from entrepreneurial activity, which are collected through taxes, obtaining very high wages. Moreover, for high values of $q_{t}$, oblique transmission also favors the spread of non-entrepreneurial preferences.

In Fig. 2, we can see the direction of changes in the proportion of entrepreneurs for different values of $q_{t}$ and $H$.

Summarizing, the results obtained in the two previous propositions show how the persistence of the levels of entrepreneurship is determined by the initial proportion of entrepreneurs in the society and by the productivity of the entrepreneurial sector. If the economy starts with a low proportion $q_{0}$ of entrepreneurs in the population, or with an initial low level of productivity $H\left(H<H^{\prime}\right)$, then it will get trapped in the 
long run in a traditional steady state equilibrium $\left(q^{c}\right)$. The persistence of high levels of entrepreneurship in an economy can also be explained by our results. If entrepreneurs are the majority in the population $\left(q_{0}>1 / 2\right)$ and the productivity is sufficiently high, the economy will settle down in an entrepreneurial equilibrium.

\subsection{The role of taxes}

The deep determinants driving the convergence to one steady-state equilibrium or the other are the level of taxes and the level of productivity of the entrepreneurial sector. If the level of productivity $H$ is very low $\left(H<H^{\prime}\right)$, then the society will get trapped in the long run in a traditional steady-state equilibrium $\left(q^{c}\right)$. However, when productivity is sufficiently high $\left(H \geq H^{\prime}\right)$, the introduction or not of confiscatory taxes in some generation is driving the dynamics. More precisely, if confiscatory taxes are set by some generation and maintained over time, the economy converges to the traditional steady state. Alternatively, if non-confiscatory taxes are implemented by all generations along the trajectory of the dynamics, the economy converges to the entrepreneurial steady state.

Remark 1 The tax policy path implemented by all generations determines the convergence to a traditional or entrepreneurial equilibrium.

In order to see the intuition, let us consider that the same tax policy is implemented for any distribution of preferences in the population. For instance, if confiscatory taxes are set for any $q_{t}$ in all periods, the traditional equilibrium with $q^{c}<1 / 2$ becomes the global attractor of the dynamics. That is, for any initial condition of the economy $q_{0}$ the dynamical system converges to the steady state $q^{c}$. Similarly, for a permanent non-confiscatory tax policy $(\tau=$ $1 / 2)$, the entrepreneurial equilibrium with $q^{e}>1 / 2$ becomes the global attractor of the dynamics. Obviously, an exogenous and permanent change in tax policy can move the economy from one steady state to the other. For instance, suppose that an economy is trapped in a traditional equilibrium because of a confiscatory tax policy. A permanent change to a non-confiscatory tax policy will drive the economy to an entrepreneurial equilibrium with high levels of productivity and entrepreneurship.

\section{Comparison of the traditional and entrepreneurial equilibria}

In this Section, we compare the two steady states, focusing on the aggregate income of the economy, as well as the incomes obtained by entrepreneurs and non-entrepreneurs. That is, we will analyze the size and distribution of aggregate welfare. We use again the superscript $e$ to denote the characteristics of the entrepreneurial equilibrium, and the superscript $c$ stands to denote those of the traditional equilibrium. Let us assume that the psychological payoff from entrepreneurship has an upper bound,

$\gamma<\frac{H^{2}}{81 \beta}+\frac{10}{9} R$

(Assumption 2)

Assumption 2 implies that we do not consider in our analysis the case where the psychological payoff from entrepreneurship is so high that parents will always prefer that their offspring become entrepreneurs under any circumstance.

Proposition 4 Suppose that Assumption 2 holds,

1. The administration is more efficient in the entrepreneurial equilibrium than in the traditional equilibrium: $e^{e}>e^{c}$. 2. Civil servants' payoff is higher in the entrepreneurial equilibrium than in the traditional equilibrium: $y_{C}^{e}>y_{C}^{c}$.

3. Entrepreneurs' payoff is higher in the entrepreneurial equilibrium than in the traditional equilibriumA: $y_{E}^{e}>y_{E}^{c}$.

Proof See Appendix.

Thus, in the entrepreneurial equilibrium, the Administration is more efficient. Hence, the probability of success of risky entrepreneurship is higher than in the traditional equilibrium. In addition, payoffs are higher both for entrepreneurs and for civil servants. Since in the traditional sector the payoff $R$ is always the same, per capita incomes are higher in the entrepreneurial equilibrium. The social welfare function is given by the aggregation of the income obtained by each type: $q y_{E}+(1-q)\left(\frac{1}{3(1-q)} y_{C}+\frac{2-3 q}{3(1-q)} R\right)$. Therefore, it easily follows that social welfare is higher in the entrepreneurial equilibrium. Given the choice, both civil servants and entrepreneurs would prefer to be in an entrepreneurial equilibrium. Thus Corollary 1 follows from Proposition 4. 
Corollary 1 Social welfare is higher in the entrepreneurial equilibrium than in the traditional equilibrium.

If Assumption 2 does not hold, the incentives for socialization of entrepreneurial parents, even in a society with a majority of non-entrepreneurs, would be so high that the traditional equilibrium would be characterized by a relatively high proportion of entrepreneurs (although in a minority) and, given the confiscatory taxes, the administration might show a high level of efficiency and obtain a high monetary income for the bureaucracy.

Another issue is the distribution of this welfare among the different types of individuals in each steady state. In the traditional equilibrium non-entrepreneurs will be better off than entrepreneurs because they appropriate all the profits generated by the entrepreneurial sector through confiscatory taxes. The opposite happens in the entrepreneurial equilibrium.

Proposition 5 In the entrepreneurial equilibrium, entrepreneurs have a higher utility than nonentrepreneurs: $U_{E}^{e}>U_{N}^{e}$, and a higher monetary payoff than civil servants, $y_{E}^{e}>y_{C}^{e}$.

Proof See Appendix.

According to this proposition, entrepreneurs obtain a higher expected utility than non-entrepreneurs in the entrepreneurial equilibrium. This result is in line with the theory of social legitimation (Etzioni 1987), according to which economies with more entrepreneurs create an environment that is more favorable to entrepreneurship. Notice additionally that, in the entrepreneurial equilibrium, civil servants have a lower income than entrepreneurs.

\section{Concluding remarks and discussion}

This paper presents a theory that explains the persistence of differences between levels of entrepreneurship across countries or regions. Empirical evidence shows that the ranking of countries by level of entrepreneurship does not change over the years for long periods of time (Freytag and Thurik 2007). The main result of the study is that taxes on entrepreneurial profits are crucial to lead an economy towards either an entrepreneurial or a traditional equilibrium. The level of taxes, if decided by majority voting, depends on the proportion of entrepreneurs among the population. Due to the interdependence and the intertemporal reinforcement among taxes, Administration performance, productivity, and transmission of preferences, the economy gets trapped close to the initial situation.

In an entrepreneurial equilibrium, there is a majority of entrepreneurs in the population. The distribution of preferences does not change because the socialization efforts are equal for both types of individuals. The entrepreneur majority implements a tax policy that maximizes their expected profits by giving the appropriate incentives for efficiency to the public administration. The high net payoff obtained by the entrepreneurial activities provides strong incentives for cultural socialization to entrepreneurship preferences. But in this steady state, there are also equally strong incentives for socialization to non-entrepreneur preferences, because the wage for civil servants (designed to sustain their high level of efficiency) is very high. The high levels of income obtained by entrepreneurs and civil servants are sustained by a high efficiency of the bureaucracy.

In an traditional equilibrium, there is a majority of non-entrepreneurs in the population. The nonentrepreneur majority implements a confiscatory tax policy. The socialization effort of entrepreneur parents and non-entrepreneur parents equalize in this steady state thanks to both oblique cultural transmission and the low income that can be obtained by routine producers. Both factors provide incentives for socialization effort to entrepreneurial preferences.

Social welfare is higher in an entrepreneurial equilibrium. In line with studies that link entrepreneurship to economic growth, both the efficiency of the entrepreneurial sector and the per capita income will be higher in the entrepreneurial equilibrium than in the traditional equilibrium.

Therefore, if individuals are forward-looking and are concerned about the welfare of future generations, they will try to implement some tax reform in order to drive the economy to an entrepreneurial equilibrium. Namely, a coalition between entrepreneurs and civil servants could be formed to agree on a credible commitment to never set confiscatory taxes in the future and to compensate the short-run losses for nonentrepreneurs with a subsidy. Obviously this intergenerational and interclass coalition suffers from the usual time-inconsistency problem. In other words, this commitment or promise is clearly non-credible. However, there are ways to establish credible commitments. 
For instance, constitutional limits on the tax rate policy and on the civil servants future wages can be established. Alternatively, another way to build credibility is the integration in a supranational organization (international club), for instanc, the European Union, where confiscatory taxes are not permitted. For different reasons, these mechanisms are very costly to reverse. In case of a constitutional reform, because it requires a qualified majority to do so. In case of the participation in an international club, because exit can be very costly in terms of losing the trading advantages obtained from being a member of the club.

Another mechanism of commitment that operates to guarantee the absence of confiscatory taxes is the degree of external openness of the economy. Notice that in our model a closed economy is implicitly assumed. But if the economy is open (and in particular if it belongs to a supranational economic region with free trade and free movement of persons and capital), then there will be an obvious restriction on the behavior of a non-entrepreneur majority that puts a limit on tax rates: talent and entrepreneurship can migrate to another country. These possible extensions of our model highlight again the crucial role played by taxes on the final long-run equilibrium achieved by an economy.

Acknowledgments G. Olcina and L. Escriche acknowledge financial support from the Spanish Ministry of Economy and Competitiveness project, ECO-2014-58297-R, ECO-2017-87245-R and the ERC project-TECTACOM. E.M. Tur thanks the Broman Foundation for financial support.

Open Access This article is distributed under the terms of the Creative Commons Attribution 4.0 International License (http:// creativecommons.org/licenses/by/4.0/), which permits unrestricted use, distribution, and reproduction in any medium, provided you give appropriate credit to the original author(s) and the source, provide a link to the Creative Commons license, and indicate if changes were made.

\section{Appendix}

The time subscript has been removed in the proofs

Proof of Proposition 1 The individuals of the majority win the vote on taxes. The manager of the administration decides on the level efficiency and the size of the administration $(e, \alpha)$ with the objective of maximizing the total payoff of the bureaucracy: $\tau$ Hqe $\alpha(1-$ $\alpha)-\alpha \frac{\beta e^{2}}{2}$, subject to $(1-q) \geq \alpha$. Let us denote this function as $f=\tau \operatorname{Hqe} \alpha(1-\alpha)-\alpha \frac{\beta e^{2}}{2}$. The first-order conditions for an interior solution are follows:

$$
\begin{aligned}
& f_{e}=0 \rightarrow \tau q H\left(1-\alpha^{*}\right) \alpha^{*}-\alpha^{*} \beta e^{*}=0 \rightarrow e^{*}=\tau \frac{q H\left(1-\alpha^{*}\right)}{\beta}, \\
& f_{\alpha}=0 \rightarrow \tau q H e\left(1-2 \alpha^{*}\right)-\frac{\beta e^{*}}{2}=0 \rightarrow \alpha^{*}=\frac{\tau 2 q H-\beta e^{*}}{4 \tau H \beta} .
\end{aligned}
$$

Solving for the optimal levels $\left(e^{*}, \alpha^{*}\right)$, we obtain the following:

$$
\begin{aligned}
e^{*}(\tau) & =\tau \frac{2 q H}{3 \beta}, \\
\alpha^{*} & =\frac{1}{3} .
\end{aligned}
$$

And, it is easy to check that it is a maximum since: $f_{\mathrm{ee}}=-\alpha \beta<0, f_{\alpha \alpha}=-2 \tau H q e^{*}<0$. Furthermore, $f_{\text {ee }} \times f_{\alpha \alpha}>\left(f_{e \alpha}\right)^{2}$ since

$$
\begin{aligned}
2 \alpha^{*} \beta \tau H q e^{*}> & \left(\tau H q-2 \tau H q \alpha^{*}-\beta e^{*}\right)^{2} \\
& \rightarrow \frac{8}{9}(\tau H q)^{2}>\frac{5}{9}(\tau H q)^{2} .
\end{aligned}
$$

If $1-q<1 / 3$, then the maximum is in the boundary of the set of feasible solutions, $\alpha^{*}=1-q$ and the effort level is $e^{*}(\tau)=\tau \frac{q H^{2}}{\beta}$. Substituting the tax rate ( $\tau=1$ or $\tau=1 / 2$ ), we obtain the administration efficiency in each case. The payoffs for both types of agents are determined by equations (1) and (3). There are two possible equilibria within a generation:

1. Equilibrium if non-entrepreneurs are the majority, $q<1 / 2$, characterized by the following:

$$
\begin{aligned}
\tau & =1, \\
e & =\frac{2 q H}{3 \beta}, \\
y_{C} & =\frac{2 q^{2} H^{2}}{9 \beta}, \\
y_{E} & =0 .
\end{aligned}
$$

2. Equilibrium if entrepreneurs are the majority, $q \geq$ $1 / 2$, characterized by the following:

$$
\begin{gathered}
\tau=1 / 2, \\
e= \begin{cases}\frac{q H}{3 \beta} & \text { if } q \leq 2 / 3 \\
\frac{q H^{2}}{2 \beta} & \text { if } q>2 / 3,\end{cases} \\
y_{C}=\left\{\begin{array}{l}
\frac{q^{2} H^{2}}{18 \beta} \text { if } q \leq 2 / 3 \\
\frac{q^{4} H^{2}}{8 \beta} \text { if } q>2 / 3,
\end{array}\right. \\
y_{E}=\left\{\begin{array}{cc}
\frac{q H^{2}}{27 \beta} & \text { if } q \leq 2 / 3 \\
\frac{q^{3}(1-q) H^{2}}{4 \beta} & \text { if } q>2 / 3 .
\end{array}\right.
\end{gathered}
$$


Proof of the optimal socialization effort choice of parents (subsection 4.2)

Parents of type $i$ choose the socialization effort $d_{t}^{i}$ at generation $t$ that maximizes the following:

$\max _{d_{t}^{i}}\left\{P_{t}^{\mathrm{ii}} V^{\mathrm{ii}}+P_{t}^{\mathrm{ij}} V^{\mathrm{ij}}-c\left(d_{t}^{i}\right)\right\}$.

The first order condition is as follows :

$\frac{\partial P_{t}^{\mathrm{ii}}}{\partial d_{t}^{i}} V^{\mathrm{ii}}+\frac{\partial P_{t}^{\mathrm{ij}}}{\partial d_{t}^{i}} V^{i j}=k d_{t}^{i}$.

In order to guarantee $d_{t}^{i} \in[0,1)$, a sufficient condition is $k>\max \left\{\Delta V^{E}, \Delta V^{N}\right\}$, i.e., the marginal cost of effort 1 is greater than the value of cultural assimilation. In that case, the marginal cost for parents to ensure that their child acquires the same preferences as their own is too high.

Differentiating the transition probabilities in Eq. 8 and substituting in the first order condition, we obtain the parents' socialization efforts as follows:

$$
\begin{aligned}
d_{t}^{* E} & =\frac{1}{k}\left(V^{\mathrm{EE}}-V^{\mathrm{EN}}\right)\left(1-q_{t}\right) \\
d_{t}^{* N} & =\frac{1}{k}\left(V^{\mathrm{NN}}-V^{\mathrm{NE}}\right) q_{t} .
\end{aligned}
$$

Hereafter, to simplify the notation, we do not include this auxiliary parameter $k$, although it should be remembered that it is implicit in the formulas. When $d_{t}^{E}-d_{t}^{N}$ is written, one should actually read $k\left(d_{t}^{E}-d_{t}^{N}\right)$.

Proof of Proposition 2: Equilibrium in the long run when non-entrepreneurs are majority.

In a non-entrepreneurial economy $(q<1 / 2)$, where the majority of non-entrepreneurs vote for confiscatory taxes $\tau=1$, the values of cultural assimilation are follows:

$$
\begin{aligned}
& \Delta V^{E}=\gamma-y^{N} \rightarrow \Delta V^{E}=\gamma-\left[\alpha y^{C}+(1-\alpha) R\right] \\
& \Delta V^{N}=\gamma+y^{N} \rightarrow \Delta V^{N}=\gamma+\left[\alpha y^{C}+(1-\alpha) R\right] .
\end{aligned}
$$

The difference between the socialization efforts of the two types of parents is as follows:

$$
\begin{aligned}
d^{E}-d^{N} & =(1-q) \Delta V^{E}-q \Delta V^{N} \\
& =\Delta V^{E}-q\left(\Delta V^{E}+\Delta V^{N}\right)= \\
& =\gamma(1-2 q)-y_{N} .
\end{aligned}
$$

If $q<1 / 2$, the payoffs are $y_{C}=\frac{2 q^{2} H^{2}}{9 \alpha \beta}, y_{E}=0$ (see proof of Proposition 1), therefore

$d^{E}-d^{N}=\gamma(1-2 q)-\left[\frac{2 q^{2} H^{2}}{27(1-q) \beta}+\frac{2-3 q}{3(1-q)} R\right]$.

We have to prove that $q^{c}$ effectively exists and that is unique. If $q<1 / 2$, we have the following:

$$
d^{E}-d^{N}=\underbrace{-\frac{q^{2} H^{2}}{2(1-q)^{2} \alpha \beta}-\frac{2-3 q}{3(1-q)}}_{<0} R+\underbrace{\gamma(1-2 q)}_{>0}
$$

and substituting for $q=1 / 2$ and $q=0$, the difference between socialization efforts results:

$$
\begin{aligned}
d^{E}-\left.d^{N}\right|_{q=1 / 2} & =-\frac{2 H^{2}}{54 \beta}-\frac{5}{6} R<0 \\
d^{E}-\left.d^{N}\right|_{q=0} & =\gamma-\frac{2}{3} R>0 \text { under Assumption 1 }
\end{aligned}
$$

As $d^{E}-d^{N}$ is continuous in [0,1/2], $\exists q^{c} \in(0,1 / 2)$ : $d^{E}-d^{N}=0$, and therefore at this point $\Delta q_{t}=0$.

In addition, $\frac{\partial\left(d^{E}-d^{N}\right)}{\partial q}=-\frac{2 H^{2}}{27 \beta} \frac{2(1-q)}{(1-q)^{2}}-2 \gamma-$ $\frac{R}{3(1-q) 2}<0, \forall q^{c} \in[0,1 / 2]$, therefore $d^{E}-d^{N}$ is decreasing in $[0,1 / 2]$. Therefore, this $q^{c} \in(0,1 / 2)$ is unique.

Proof of Proposition 2: Equilibrium in the long run when entrepreneurs are majority, $q \geq 1 / 2$.

In an entrepreneurial economy $(q \geq 1 / 2)$ where the majority of entrepreneurs vote for non-confiscastory taxes $\tau=1 / 2$. The values of cultural assimilation if $q_{t}<2 / 3$ are now given by the following:

$$
\begin{aligned}
\Delta V^{E} & =\gamma+\left[y^{E}-y^{N}\right] \rightarrow \Delta V^{E} \\
& =\gamma-\left(1-\frac{1}{3(1-q)}\right) R+\left[y^{E}-\frac{1}{3(1-q)} y^{C}\right], \\
\Delta V^{N} & =\gamma-\left[y^{E}-y^{N}\right] \rightarrow \Delta V^{N} \\
& =\gamma+\left(1-\frac{1}{3(1-q)}\right) R-\left[y^{E}-\frac{1}{3(1-q)} y^{C}\right] .
\end{aligned}
$$

The differences between socialization effort, considering (14) and (15) are follows:

$$
\begin{aligned}
d^{E}-d^{N}= & (1-q) \Delta V^{E}-q \Delta V^{N} \\
= & \Delta V^{E}-q\left(\Delta V^{E}+\Delta V^{N}\right) \\
= & y_{E}-\frac{1}{3(1-q)} y_{C}-\left(1-\frac{1}{3(1-q)}\right) R \\
& +\gamma(1-2 q) .
\end{aligned}
$$


If $q>2 / 3$ then $(1-q)<\alpha^{*}=1 / 3$ and all nonentrepreneurs become civil servants and $y^{N}=y^{C}$. Therefore,

$d^{E}-d^{N}=\gamma(1-2 q)+\frac{q^{3} H^{2}}{8 \beta}(2-3 q)$,

which is negative for all $q>2 / 3$.

However, if $q<2 / 3$ then

$$
\begin{aligned}
d^{E}-d^{N} & =\frac{q H^{2}}{27 \beta}-\frac{1}{3(1-q)} \frac{q^{2} H^{2}}{18 \beta} \\
& -\left(\frac{2-3 q}{3(1-q)}\right) R+\gamma(1-2 q) \\
& =\frac{2-3 q}{54(1-q) \beta} q H^{2}-\frac{2-3 q}{3(1-q)} R+\gamma(1-2 q)
\end{aligned}
$$

We have to prove that $q^{e}$ effectively exists and that is unique. We have that the first term is positive and the second is negative if $q<2 / 3$.

$d^{E}-d^{N}=\underbrace{\frac{2-3 q}{54(1-q) \beta} q H^{2}}_{>0} \underbrace{-\frac{2-3 q}{3(1-q)} R+\gamma(1-2 q)}_{<0}$

Substituting for $q=1 / 2$ and $q=2 / 3$ in this expression, we have the following:

$$
\begin{aligned}
d^{E}-\left.d^{N}\right|_{q=1 / 2} & =-\frac{1}{3}\left(R-\frac{H^{2}}{36 \beta}\right) \\
& >0 \text { if } H \geq H^{\prime}, \text { where } H^{\prime}=6 \sqrt{\beta R} \\
d^{E}-\left.d^{N}\right|_{q=2 / 3} & =-\frac{1}{3} \gamma<0 .
\end{aligned}
$$

As $d^{E}-d^{N}$ is continuous in [1/2,2/3], $\exists q^{e} \in$ $(1 / 2,2 / 3): d^{E}-d^{N}=0$, and therefore at this point $\Delta q_{t}=0$.

In addition, $\frac{\partial\left(d^{E}-d^{N}\right)}{\partial q}=-2 \gamma+\frac{R}{3(1-q)^{2}}+$ $\frac{H^{2}}{54 \beta} \frac{3 q^{2}-6 q+2}{(1-q)^{2}}<0 \forall q \in[1 / 2,2 / 3]$, taking into account that $\frac{2}{3} R<\gamma$ and that $H \geq H^{\prime}=6 \sqrt{\beta R}$; therefore, $d^{E}-d^{N}$ is decreasing in [1/2,2/3]. Hence, this $q^{e} \in(1 / 2,2 / 3)$ is unique.

Nonetheless, if $H<H^{\prime}$, the differences between socialization efforts $\left(d^{E}-d^{N}\right)$ is negative $\forall q_{t} \in$ $[1 / 2,1]$ and non-entrepreneurial traits spreads among the population. Eventually, the proportion $q_{t}$ will arise to $q_{t}<1 / 2$ and the economy converges to $q^{c}$ as proved in Proposition 2.

Proof of Proposition 4 Comparison of the traditional and entrepreneurial equilibria
Table 1 Efficiency and payoffs at the steady state equilibria

Traditional equilibrium Entrepreneurial equilibrium

\begin{tabular}{ll}
\hline$e^{c}=\frac{2 q^{c} H}{3 \beta}$ & $e^{e}=\frac{q^{e} H}{3 \beta}$ \\
$y_{C}^{c}=\frac{2\left(q^{c}\right)^{2} H^{2}}{9 \beta}$ & $y_{C}^{e}=\frac{\left(q^{e}\right)^{2} H^{2}}{18 \beta}$ \\
$y_{E}^{c}=0$ & $y_{E}^{e}=\frac{q^{1} H^{2}}{27 \beta}$
\end{tabular}

Taking into account the steady state points $q^{c}$ and $q^{e}$ from Propositions 2 and 3, we calculate the administration efficiency, civil servants' payoff, and entrepreneurs' payoff in each equilibrium. Table 1 provides the results to facilitate the comparison

1. Comparing administration efficiency, we have that $e^{e}>e^{c}$ if $\frac{q^{e} H}{3 \beta}>\frac{2 q^{c} H}{3 \beta} \rightarrow q^{e}>2 q^{c}$. We know that $1 / 2<q^{e}<2 / 3$ and $q^{c}<1 / 2$. Therefore, it must hold that $1 / 2>2 q^{c}$. A sufficient condition is $q^{c}<1 / 4$. If $d^{E}-\left.d^{N}\right|_{q=1 / 4}<0$, then $q^{c}<1 / 4$. The difference between socialization efforts for $q<1 / 2$ is given by the following:

$d^{E}-d^{N}=-\frac{2 q^{2} H^{2}}{27 \beta(1-q)}-\frac{2-3 q}{3(1-q)} R+\gamma(1-2 q)$ and evaluated in $q=1 / 4$ is

$d^{E}-\left.d^{N}\right|_{q=1 / 4}=-\frac{H^{2}}{162 \beta}-5 / 9 R+1 / 2 \gamma$.

Recall that for $H<H^{\prime}$, there is only a steady state $q^{c}$. Therefore, we analyze the case where $H \geq H^{\prime}$. Substituting for $H^{\prime}=6 \sqrt{\beta R}$, we obtain that under Assumption 2, for any $H \geq H^{\prime} \rightarrow$ $d^{E}-\left.d^{N}\right|_{q=1 / 4}<0$, which implies that $e^{e}>e^{c}$.

2. Civil servants' payoff is higher in the entrepreneurial economy than in the traditional economy: $y_{C}^{e}>y_{C}^{c}$ if $\frac{\left(q^{e}\right)^{2} H^{2}}{18 \beta}>\frac{\left(q^{c}\right)^{2} H^{2}}{9 \beta} \rightarrow q^{e}>$ $2 q^{c}$, which holds if $e^{e}>e^{c}$ that has been proved above.

3. It is trivial because $y_{E}^{c}=0$

Proof of Proposition 5 First, we compare the utilities $U_{E}^{e}$ and $U_{N}^{e}$ :

$U_{E}^{e}=\frac{q^{e} H^{2}}{27 \beta}+\gamma$

$U_{N}^{e}=\frac{\left(q^{e}\right)^{2} H^{2}}{54\left(1-q^{e}\right) \beta}+\frac{2-3 q^{e}}{3\left(1-q^{e}\right)} R$. 
Comparing the first terms, we obtain that $\frac{q^{e} H^{2}}{27 \beta}>$ $\frac{\left(q^{e}\right)^{2} H^{2}}{54\left(1-q^{e}\right)^{2} \beta}$ if $q^{e}<\frac{2}{3}$ which holds because $q^{e} \in$ $(1 / 2,2 / 3)$. Moreover, $\gamma>\frac{2-3 q^{e}}{3\left(1-q^{e}\right)} R \forall q^{e} \in$ $(1 / 2,2 / 3)$ as $\gamma>\frac{2}{3} R$ because of Assumption 1, then $U_{E}^{e}>U_{N}^{e}$.

Second, we compare $y_{E}^{e}$ with $y_{C}^{e}$. The payoff of entrepreneurs is higher than the payoff of a civil servant if $\frac{q^{e} H^{2}}{27 \beta}>\frac{\left(q^{e}\right)^{2} H^{2}}{18 \beta} \rightarrow q^{e}<2 / 3$ which holds because $q^{e} \in(1 / 2,2 / 3)$.

\section{References}

Acs, Z., \& Mueller, P. (2008). Employment effects of business dynamics: mice, gazelles and elephants. Small Business Economics, 30, 85-100. https://doi.org/10.1007/s11187-0079052-3.

Acs, Z.J., \& Amorós, J.E. (2008). Introduction: the startup process. Estudios de Economía, 35(2), 121-132.

Afonso, A., Schuknecht, L., Tanzi, V. (2005). Public sector efficiency: an International omparison. Public Choice, 123(34), 321-347. https://doi.org/10.1007/s11127-005-7165-2.

Andersson, M., \& Koster, S. (2011). Sources of persistence in regional start-up rates - evidence from Sweden. Journal of Economic Geography, 11, 179-201. https://doi.org/10. 1007/s11127-005-7165-2.

Ashraf, Q., \& Galor, O. (2011). Cultural diversity, geographical isolation, and the origin of the wealth of nations, Working Paper 17640, National Bureau of Economic Research. http://www.nber.org/papers/w17640.pdf.

Audretsch, D.B., \& Thurik, R. (2001). Linking entrepreneurship to growth. OECD Science, Technology and Industry Working Papers, 2001/02, OECD Publishing. https://doi.org/10. $1787 / 736170038056$.

Autio, E. (2005). Global entrepreneurship monitor: 2005. Report on High-Expectation Entrepreneurship, Babson College and London Business School.

Bisin, A., \& Verdier, T. (2001). The economics of cultural transmission and the dynamics of preferences. Journal of Economic Theory, 97(2), 298-319. https://doi.org/10.1006/ jeth.2000.2678.

Bisin, A., \& Verdier, T. (2011b). The economics of cultural transmission and socialization. In Benhabib, J., Bisin, A., Matthew O., Jackson (Eds.) Handbook of Social Economics, Vol. 1A, The Netherlands: North-Holland, pp. 339-416.

Carree, M., van Stel, A., Thurik, R., et al. (2002). Economic development and business ownership: an analysis using data of 23 OECD countries in the period 1976-1996. Small Business Economics, 19, 271-290. https://doi.org/10.1023/ A:1019604426387.

Cavalli-Sforza, L., \& Feldman, M. (1981). Cultural transmission and evolution: a quantitative approach. Monographs in population biology, 16. Princeton: Princenton University Press.
Chakraborty, S., Thompson, J.C., Yehouec, E.B. (2016). The culture of entrepreneurship. Journal of Economic Theory, 163, 288-317. https://doi.org/10.1016/j.jet.2015.12.007.

Chlosta, S., Patzelt, H., Klein, S.B., Dormann, Ch. (2012). Parental role models and the decision to become selfemployed: the moderating effect of personality. Small Business Economics, 38, 121-138. https://doi.org/10.1007/s111 87-010-9270-y.

Ciccone, A., \& Papaioannou, E. (2007). Red tape and delayed entry. Journal of the European Economic Association, 5(23), 444-458. https://doi.org/10.1162/jeea.2007.5.2-3.444.

Cullen, J.B. (2007). Taxes and entrepreneurial risk-taking: theory and evidence for the US. Journal of Public Economics, 91(7-8), 1479-1505. https://doi.org/10.1016/j.jpubeco.2006. 12.001 .

De Paola, M. (2012). The determinants of risk aversion: the role of intergenerational transmission. German Economic Review, 14(2), 214-234. https://doi.org/10.1111/j.1468-0475. 2011.00561.x.

Delfgaauw, J., \& Dur, R. (2008). Incentives and workers' motivation in the public sector. Economic Journal, 118(525), 171-191. https://doi.org/10.1111/j.1468-0297.2007.02108.x.

Djankov, S., Ganser, T., McLiesh, C., Ramalho, R., Shleifer, A. (2010). The effect of corporate taxes on investment and entrepreneurship. American Economic Journal: Macroeconomics, 2(3), 31-64. https://doi.org/10.1257/mac.2.3.31.

Dohmen, T., Falk, A., Huffman, D., sunde, U. (2011). The intergenerational transmission of risk and trust attitudes. Review of Economic Studies, 79(2), 645-677. https://doi.org/10.1093/restud/rdr027.

Etzioni, A. (1987). Entrepreneurship, adaptation and legitimation. a macro- behavioral perspective. Journal of Economic Behavior and Organization, 8(2), 175-189. https://doi.org/ 10.1016/0167-2681(87)90002-3.

EIP (2009). OECD, co-operation and development, organisation for economic, measuring entrepreneurship: a collection of indicators, 2009 edition. Ewing Marion Kauffman Foundation Research. https://doi.org/10.2139/ssrn.1581491.

Forquesato, P. (2016). Social norms of work ethic and incentives in organizations. Journal of Economic Behavior and Organization, 128, 231-250. https://doi.org/10.1016/j.jebo. 2016.05.012.

Freytag, A., \& Thurik, R. (2007). Entrepreneurship and its determinants in across-country setting. Journal Evolutionary Economics, 17, 117-131. https://doi.org/10.1007/s00191006-0044-2.

Fritsch, M., \& Wyrwich, M. (2014). The long persistence of regional levels of entrepreneurship: Germany. Regional Studies, 48:6, 955-973. https://doi.org/10.1080/00343404. 2013.816414

Hauk, E., \& Saez-Marti, M. (2002). On the cultural transmission of corruption. Journal of Economic Theory, 107(2), 311335. https://doi.org/10.1006/jeth.2001.2956.

Hoffmann, A., Junge, M., Malchow-Mller, N. (2015). Small Business Economics, 44, 79. https://doi.org/10.1007/s11187014-9586-0.

Hundley, G. (2006). Family background and the propensity for self-employment. Industrial Relations: A Journal of Economy and Society, 45, 377-392. https://doi.org/10.1111/j. 1468-232X.2006.00429.x. 
Klapper, L., Amit, R., Guillen, M.F. (2010). Entrepreneurship and firm formation across countries. International Differences in Entrepreneurship, pp. 129-158. Chicago: University of Chicago Press.

Klapper, L., Laeven, L., Rajan, R. (2006). Entry regulation as a barrier to entrepreneurship. Journal of Financial Economics, 82(3), 591-629. https://doi.org/10.1016/j. jfineco.2005.09.006.

Laspita, S., Breugst, N., Heblich, S., Patzelt, H. (2012). Intergenerational transmission of entrepreneurial intentions. Journal of Business Venturing, 27, 414-434.

Lee, Y., \& Gordon, R.H. (2005). Tax structure and economic growth. Journal of Public Economics, 89(5-6), 1027-1043. https://doi.org/10.1016/j.jbusvent.2011.11.006.

Lindquist, M.J., Sol, J.oeri., Van Praag, M. (2015). Why do entrepreneurial parents have entrepreneurial children? Journal of Labor Economics, 33(2), 269-296. https://doi.org/10.1086/678493.

Minniti, M. (1999). Entrepreneurial activity and economic growth. Global Business and Economics Review, 1(1), 3142. https://doi.org/10.1504/GBER.1999.006134.

Moskovitz, T., \& Vissing-Jorgensen, A. (2002). The returns to entrepreneurial investment: a private equity premium puzzle? American Economic Review, 92, 745-78. https://doi.org/10.1257/00028280260344452.

Mueller, P., Van Stel, A., Storey, D.J. (2008). The effect of new firm formation on regional development over time: the case of Great Britain. Small Business Economics, 30, 59-71. https://doi.org/10.1007/s11187-007-9056-z.
Reynolds, P.D., Hay, M., Camp. M.S. (1999). Global entrepreneurship monitor. Kansas City: Kauffman Center for Entrepreneurial Leadership.

Reynolds, P.D., Bygrave, W.D., Autio, Cox, L.W., Hay, M. (2002). Global entrepreneurship monitor, 2002 Executive Report, Wellesley, MA: Babson College.

Schumpeter, J.A. (1934). The theory of economic development: an inquiry into profits, capital, credit, interest and business cycle. Cambridge: Harvard University Press.

van Stel, A., Carree, M., Thurik, R. (2005). The effect of entrepreneurial activity on national economic growth. Small Business Economics, 24(3), 311-321. https://doi.org/10.1007/s11187-005-1996-6.

van Stel, A., \& Suddle, K. (2008). The impact of new firm formation on regional development in the Netherlands. Small Business Economics, 30, 31-47. https://doi.org/10.1007/s11187-007-9054-1.

Wennekers, S., \& Thurik, R. (1999). Linking entrepreneurship and economic growth. Small Business Economics, 13, 2755. https://doi.org/10.1023/A:1008063200484.

Wennekers, S., van Wennekers, A., Thurik, R., et al. (2005). Nascent entrepreneurship and the level of economic development. Small Business Economics, 24, 293-309. https://doi.org/10.1007/s11187-005-1994-8.

Wyrwich, M. (2015). Entrepreneurship and the intergenerational transmission of values. Small Business Economics, 45, 191-213. https://doi.org/10.1007/s11187-015-9649-x. 